\title{
IODP New Ventures in Exploring Scientific Targets (INVEST): Defining the New Goals of an International Drilling Program
}

\author{
Wolfgang Bach, Christina Ravelo, Jan Behrmann, Gilbert Camoin, Robert Duncan, \\ Katrina Edwards, Sean Gulick, Fumio Inagaki, Heiko Pälike, and Ryuji Tada
}

doi:10.2204/iodp.sd.9.12.2010

\section{Introduction}

The INVEST conference, an international meeting to define the scientific goals and required technology for a new ocean drilling program, was held at the University of Bremen on 22-25 September 2009. Based on the large attendance and vigorous engagement of scientists in the discussion of new science/technology ideas, INVEST was extremely successful. Initially 400 participants were expected, but the INVEST steering and organization committees were thrilled to see a much larger number of scientists flock to Bremen to demonstrate their support and enthusiasm for the continuation of an international scientific ocean drilling program. In all, 584 participants, including sixty-four students, from twenty-one nations and $>200$ institutions and agencies attended the INVEST conference. Contributions to INVEST included 103 submitted white papers that were posted on the INVEST webpage (http://www.marum.de/iodp-invest. $\mathrm{html}$ ), and breakout discussions in fifty working groups that focused on a range of topics during the course of the conference. In addition, students and early career scientists, as well as national funding agency managers and platform providers, presented a total of eighty-six posters. Interspersed with the working group and plenary sessions were twelve keynote lectures, chosen to highlight overarching themes and new directions in research and technology.

The conference was sponsored by IODP-MI, the Deutsche Forschungsgemeinschaft (DFG) and the MARUM research center. Using input from national workshops that took place in the year prior to the INVEST conference and that provided initial ideas for scientific directions and themes, the INVEST working group sessions were organized within six conference themes: 1) Co-evolution of Life and Planet, 2) Earth's Interior, Crust and Surface Interactions, 3) Climate Change - Records of the Past, Lessons for the Future, 4) Earth System Dynamics, Reservoirs and Fluxes, 5) Earth-Human-Earth Interactions, and 6) Science Implementation.

Each meeting attendee was given the opportunity to participate in three working groups: one within conference themes one through three, one within conference themes four and five, and one within conference theme six. Up to eighteen working groups met in parallel sessions. All working groups within one conference theme met to report to each other the results of the individual working group discussions. The conference theme co-chairs then met with the working group chairs and scribes to prepare a plenary presentation of the conference theme.

The steering committee, with the help of some conference session chairs, used the working group notes and plenary session presentation materials to write the INVEST conference report. The main chapters of the report are "Climate Change Impacts", "The Lithospheric Membrane: The Key Interface and Processing Zone”, "Co-evolution of Life and the Planet", and "Earth-Human-Earth Interactions". In addition, several "Cross-disciplinary Research Frontiers" were identified as being important new ocean drilling themes and were highlighted in a separate section of the report. Implementation and outreach aspects are summarized in the chapters "Technology Needs and Developments" and "Outreach, Education, and Branding". "Recommendations for the New Ocean Drilling Program" is the final chapter of the INVEST report and pertains to what the community considers desirable program architecture and science advisory structure. A brief synopsis of each of these chapters is presented below. More details on the INVEST meeting structure, white papers, background material, and the complete report can be found at the INVEST website.

\section{Climate Change Impacts}

Earth's climate results from complex interactions among Earth system components, including the atmosphere, hydrosphere, cryosphere, lithosphere, and biosphere. Variations in these systems over short and long timescales, including the way material cycles among them (e.g., carbon cycle, hydrologic cycle), result in changes to Earth's climate. Understanding how climate has changed in the past and how it will change in the future requires understanding of how the Earth system behaves over a range of conditions. Instrumental records, collected over the last century or so, are insufficient by themselves to study long-term climate change. On the other hand, ocean drilling of sediments and corals provides a unique opportunity to acquire the highresolution records of past change needed to examine and understand the baseline of natural climate variability against 
which current climate change can be compared. These records will also allow study of the behavior of the Earth system during different climate states and major climate transitions throughout the Cenozoic, as well as the origin of and mechanisms that lead to abrupt, seasonal- to millennialscale climate changes.

Fundamental climate change questions that can be addressed by ocean drilling are outlined throughout the INVEST report. This section on "Climate Change Impacts" focuses on scientific questions that, when answered, will underpin our understanding of climate change. It explores the behavior of the climate during abrupt and extreme events, the stability of ice sheets and their relationship to sea level and coastal/shoreline processes, and the impact of regional and global climate on the hydrologic cycle. In the "Earth-Human-Earth Interactions" section, climate change questions are framed in anticipation of future conditions associated with increasing levels of atmospheric carbon dioxide. Climate change questions related to tectonics and hominin evolution are explored in the "Cross-disciplinary Research Frontiers" section.

Ocean drilling can provide unprecedented insight into climatic and oceanic processes through investigation of past rapid and extreme climate events (Fig. 1). These globally significant events represent major deviations from the natural variability of Earth's climate. Extreme events originate from perturbations in a specific component of the Earth system and typically propagate through complicated feedbacks across some or all components, allowing interconnected processes to be examined and understood. Extreme and rapid events stand out in noisy sediment-derived proxy records and are thus easy to quantify. This allows investigation of dynamic system behavior, such as tipping points and thresholds. Ocean drilling remains the only means to reconstruct, at medium to high temporal resolution, the global climate evolution of the Earth system throughout the Cenozoic. Large amplitude perturbations often mark epoch boundaries and provide one of the main avenues to investigate large-scale events, including those that involve extreme climates, ecosystem turnover, and biodiversity evolution. Drilling is also the only means to study how rapid climate phenomena that occur on seasonal to millennial timescales, such as the El Niño Southern Oscillation or Dansgaard-Oeschger cycles, behave under different boundary conditions.

Only ocean drilling can provide the geologic perspective necessary to understand ice-sheet dynamics and the resulting impacts to sea level and shorelines. Over the past 100 m.y., sea-level change reflects global climate evolution from a time characterized by ephemeral Antarctic ice sheets (100 Ma to $33 \mathrm{Ma}$ ), to a time when large ice sheets occurred primarily in Antarctica (33 Ma to 2.5 Ma), and finally to a world with large Antarctic and Northern Hemisphere ice sheets (2.5 Ma to present). Over the last $\sim 800 \mathrm{kyr}$, the cyclic growth and decay of continental ice sheets induced rapid sea-level change with maximum amplitudes of 120-140 m at intervals of $100 \mathrm{kyr}$. Ice volume fluctuations can be inferred from eustatic

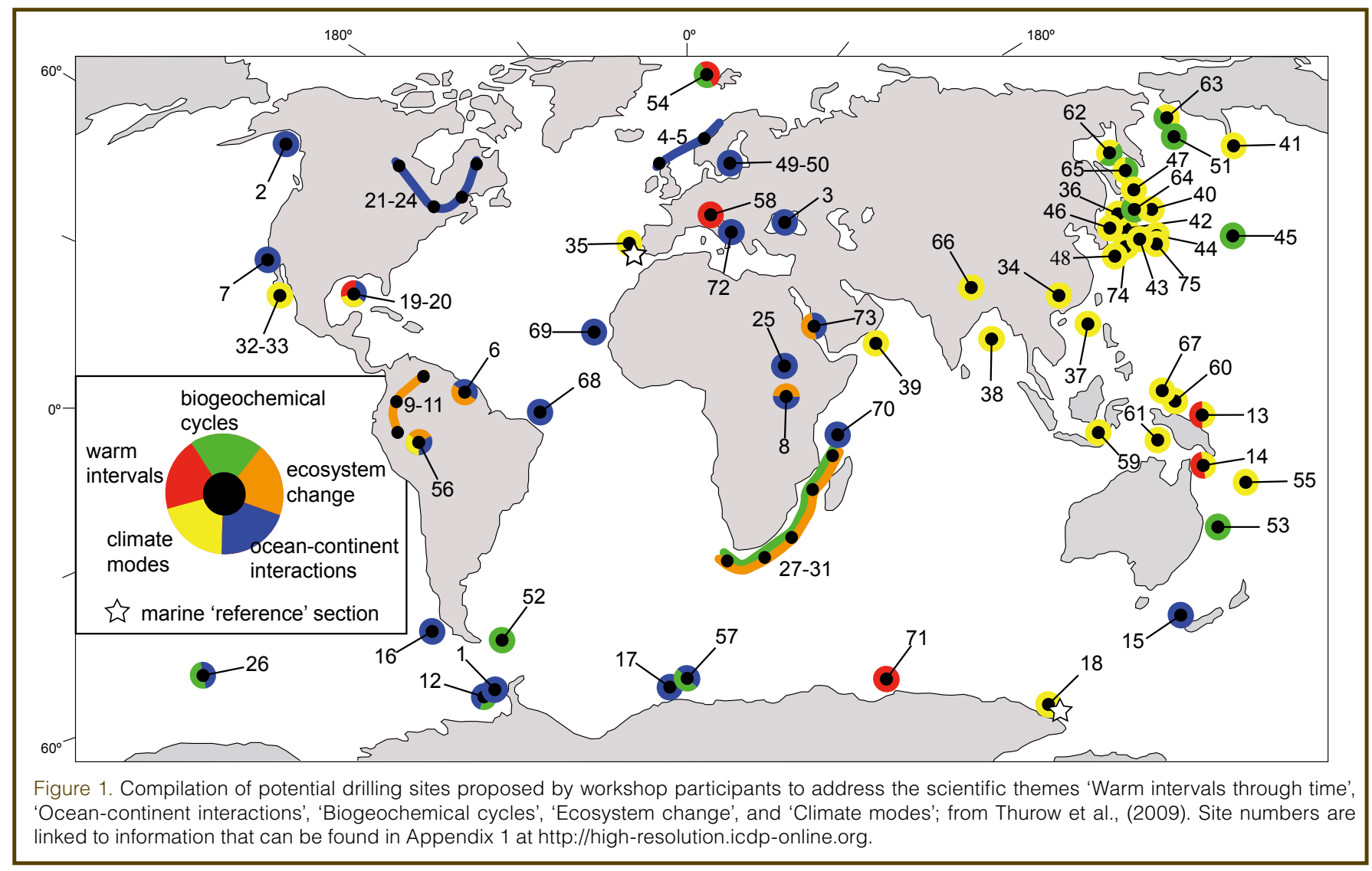


sea-level curves deciphered through comparison of regional sea-level records from various latitudes and tectonic settings. For example, observations from sites distal to glaciated regions (i.e., the "far field") are less affected by isostatic deformation and therefore better suited to constrain glacial eustasy, whereas sea-level data from sites proximal to former ice sheets (i.e., the "near field") provide information on local ice-sheet dynamics.

Understanding the processes that control changes in the hydrologic cycle is one of the most pressing issues in climate change research because changes in precipitation and evaporation impact the salinity/ density distribution in the surface ocean, ecosystems on land, floods, aridification, water resources, and climate-vegetation feedbacks. A comprehensive examination of climatic controls on the hydrologic cycle requires the study of long-term trends and variability over a range of climatic states. In fact, even small global temperature changes impact the energy balance in tropical regions,

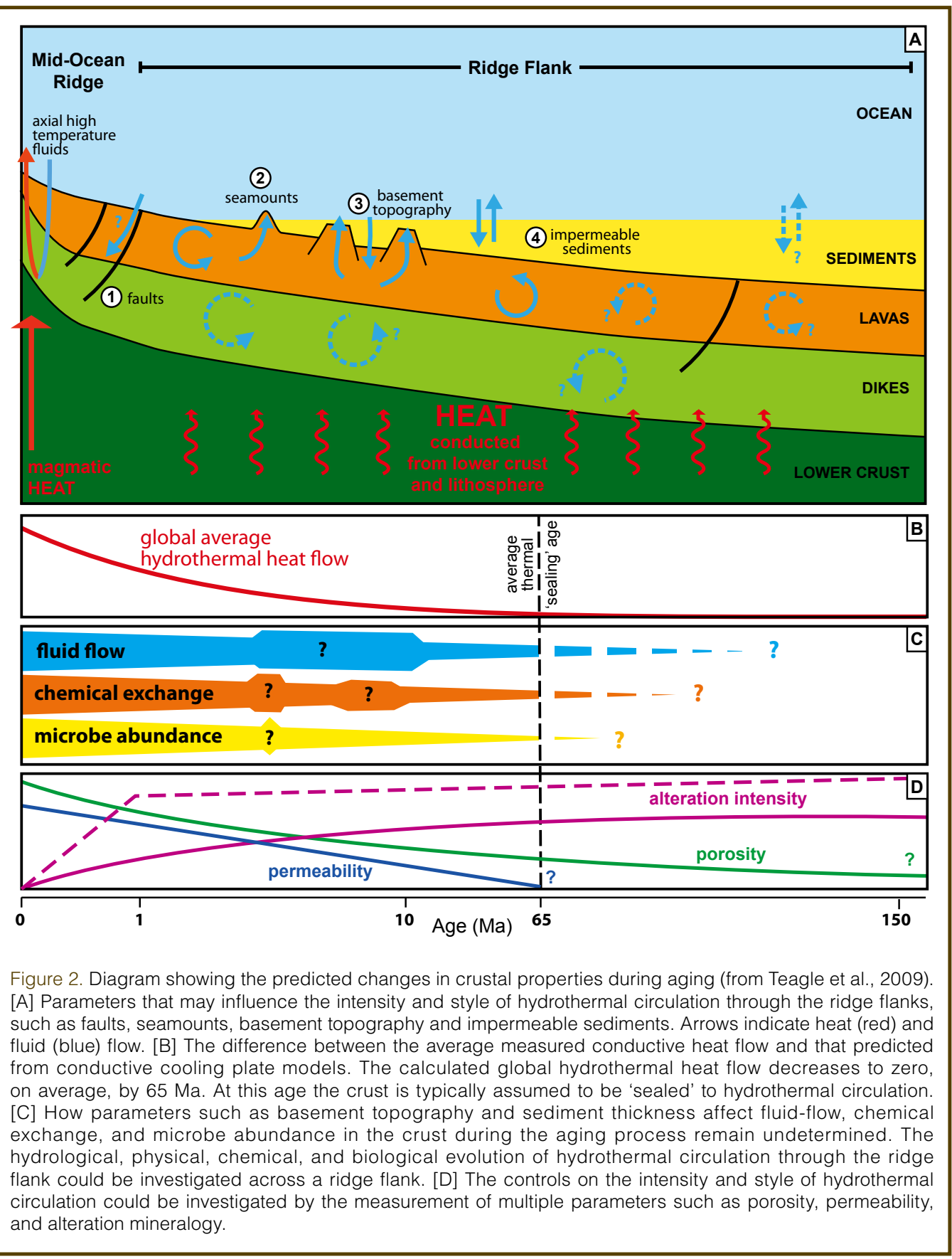
resulting in changes in

evaporation and storm and hurricane activity. In the midlatitudes, changes in atmospheric thermal gradients can impact atmospheric circulation, the location of storm tracks, and the intensity of storms. There is an urgent need to understand controls on the Intertropical Convergence Zone, climate oscillation modes and their behavior during different mean climate states, wind-driven upper ocean circulation and its coupling to atmospheric forcing, monsoon dynamics, and the relationship between precipitation patterns, density stratification, and biogeochemical processes, to name a few. Future ocean drilling is absolutely necessary to obtain the records needed to constrain past changes in surface ocean conditions associated with major changes in large-scale atmospheric circulation. This must be complemented by continental climate reconstructions obtained from drilling sediments on continental margins and on land. Finally, ocean drilling studies focused on the hydrologic cycle should be used to validate regional climate models used to predict climate change and its associated impact on water resources.

\section{The Lithospheric Membrane: The Key Interface and Process Zone}

Our tectonically active planet evolves by chemical and physical changes from the core and mantle, through the lithosphere to the ocean and atmosphere. Flow of material and energy among these reservoirs drives both gradual changes in the Earth's structure and composition, as well as extremely rapid volcanic events that impact Earth's environment. The lithosphere is the major interface between the solid interior 
of the Earth and the exterior hydrosphere/atmosphere/ biosphere (Fig. 2). Quantifying the fluxes mediated by the lithospheric processing zone is crucial for understanding the state and evolution of our planet, and ocean drilling provides a key tool in this endeavor.

From direct sampling we can examine the fundamental steady-state processes of ocean crust accretion, plate aging, and recycling, as well as intermittent events such as eruptions of large igneous provinces and rifting of continents. These processes affect the presence and state of resources that society depends upon-including sources of energy, fresh water, and nutrients-but they also create deleterious effects on society through earthquakes, tsunamis, and volcanic eruptions.

It is timely to stress that many of the things to be learned about the "lithospheric membrane" of the Earth are of great societal relevance. Understanding initiation of plate boundaries and evolution of plates is fundamental to learning how the Earth works and how the continents we live upon were formed and evolve. Plate boundary formation and related volcanism have impacted past climate and may yield information about agents of climate change. Rifted continental margins host major hydrocarbon reservoirs that are an essential energy resource. Subduction zone hydration-dehydration cycling affects earthquakes and volcanic hazards. Hydrothermal systems form polymetallic sulfide deposits of potential economic interest and also host microorganisms that may be useful for bioengineering. Finally, the ocean crust provides vast opportunities for $\mathrm{CO}_{2}$ capture and storage.

Understanding hydrothermal transfers of heat and mass between the lithosphere and hydrosphere/atmosphere on a global scale has been identified as a high-priority overarching research question. Seawater circulation facilitates microbial growth within the ocean floor and is critical to the transport and distribution of microorganisms; however, the size, activity, and connectivity of the intracrustal oceanic biosphere and its influence on global geochemical and biogeochemical cycles are unknown. Investigation of the coupling between hydrogeological, geochemical, thermal, mechanical, and biological processes and their relationship to the architecture and physical nature of oceanic lithosphere is essential. Of primary importance is addressing the nature of the Mohorovicić discontinuity (Moho), a first-order geophysical interface within our planet, which is uncertain in slow-spreading mid-ocean ridge environments. It could be an igneous boundary or a serpentinization front-a difference with profound consequences for the chemical and rheological properties of the lithosphere. As much as one-quarter of the seafloor exposed at slow-spreading mid-ocean ridges is a heterogeneous assemblage of peridotite and gabbroic lithologies, which is hydrothermally more reactive and undergoes greater changes in physical properties than layered basaltic crust. To understand ocean-crust composi- tion, structure, and evolution, it is essential to drill a complete crustal section across the Moho and into the shallow mantle at a fast-spreading ridge. Complete sampling is also necessary to provide in situ confirmation of geophysical imaging of the ocean crust.

When oceanic lithosphere is recycled during subduction and plate collision, sediments may be scraped off, and ocean crust can be accreted to a continent or island arc. Deep in subduction zones, dehydration reactions and melting of subducting sediments and occasionally the upper crust produce continental or oceanic volcanic arcs. Both of these processes can effectively transfer crustal material, fluids, and volatiles from the geologically transient oceanic lithosphere to more permanent continental crust. Ocean drilling is a critical tool necessary to investigate the relative roles of these processes and the magnitudes of element fluxes. Of crucial importance in determination of input fluxes are reliable estimates of the chemical and mineralogical state of the subducting ocean crust. Additionally, subduction zones produce some of the most significant geologic hazards to society including the highest magnitude earthquakes, the greatest tsunamis, and the most explosive eruptions.

Formation, hydrothermal alteration, and subduction of ocean crust generate secular chemical and physical changes throughout the crust and mantle, as well as in the oceanatmosphere system. Large igneous provinces and hot spot trails are profound examples of massive mantle-crust exchanges and how these vary in time and space. At intermittent intervals, the emplacement of oceanic plateaus and formation of volcanic rifted margins produce significant chemical effects in the ocean and atmosphere. Particularly intense periods of volcanic activity appear to correlate with long-term changes in geodynamic behavior, which could involve interactions between the core and the deep mantle.

Many questions still need to be answered for us to better understand the Earth system. To address these we need to quantify fluxes and interplay within the mantle-crust-ocean system (physical, chemical, and biological) and monitor fault-driven processes. We also need to obtain a better understanding of the components of a subduction zone system that control seismic behavior, which in turn affects the level of hazard posed by the plate boundary. Ocean drilling will continue to significantly contribute to our understanding of these processes.

\section{Co-Evolution of Life and the Planet}

Scientific ocean drilling is poised to offer transformative advances to disciplines within the life sciences and provide insight into how life operates and interacts with Earth processes at and below the seafloor, both today and in the past. In particular, the study of paleoenvironmental controls on marine paleoecosystems through the Cenozoic and of extant 
life in rock and sediments can best be studied through ocean drilling.

Exploration of deeply seated microbial populations has revealed active, extant populations of microbes down to $1.6 \mathrm{~km}$ depth. These sedimentary and crustal habitats are vast in scale, physically and chemically diverse, and together represent the largest biome on Earth. A major challenge in the study of subseafloor life is the need to develop a more comprehensive understanding of the microbes that live there. Future research should reveal the biodiversity of the deep biosphere (Fig. 3), as well as the degree to which it is connected to surface biomes. Metagenomics, observatories, and other emerging technologies will play a significant role in the advancement of our understanding of the function and form of

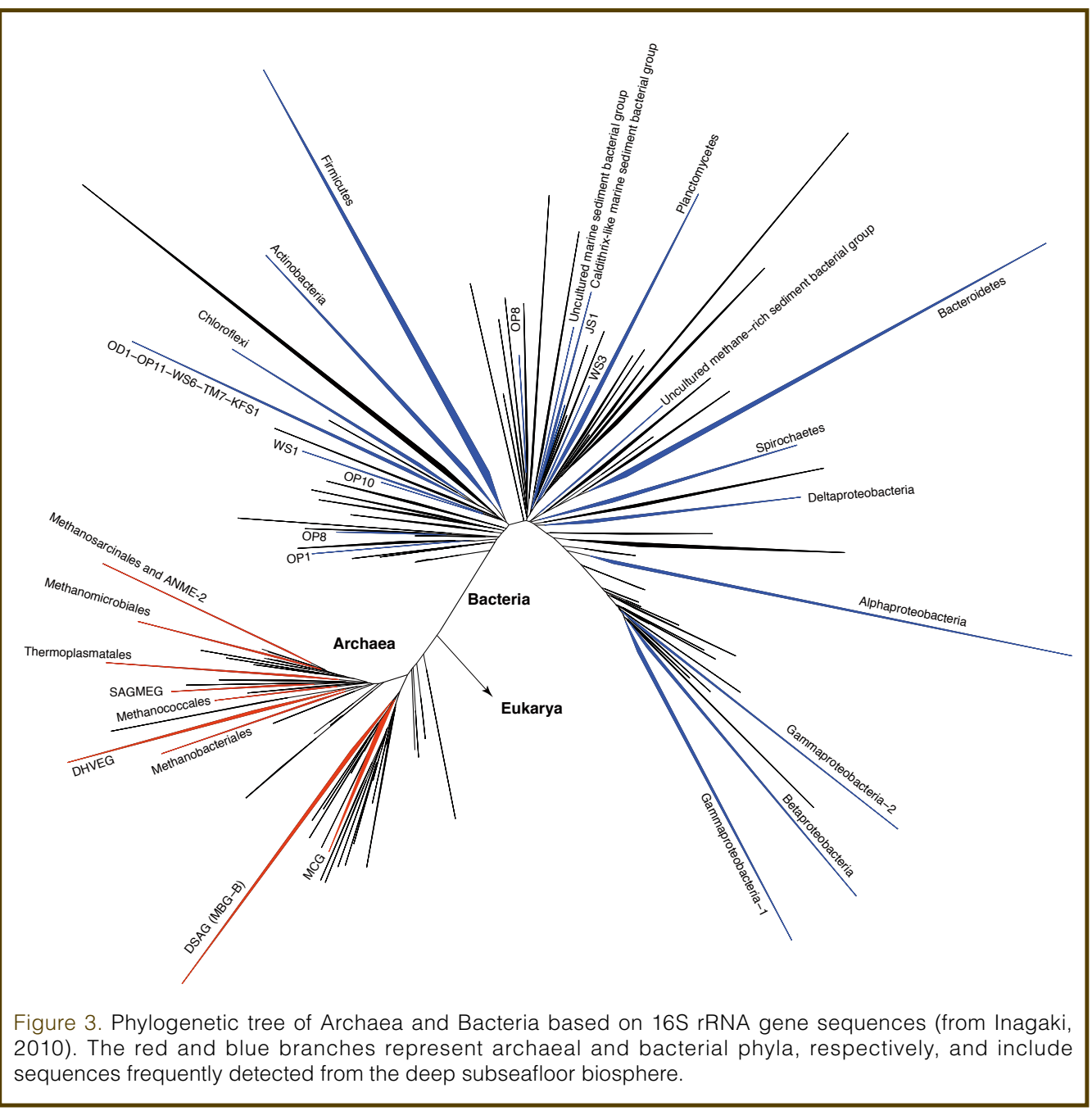
extant life in the subsurface.

Advances in our knowledge of subsurface life from past ocean drilling have principally arisen as opportunistic ventures, where a microbiologist would sail on an expedition focused on other scientific objectives. This has resulted in a significantly skewed data set. This view can be changed in the future by utilizing both opportunistic and targeted drilling expeditions for deep biosphere research. A legacy sampling program would also fill critical gaps and lead to a more comprehensive understanding of the largest biome on Earth.

New approaches and dedicated expeditions will also reveal the physiological function and activity of the deep biosphere and provide a quantitative first-order understanding of the rates and magnitude of the biogeochemical processes that occur there. How these processes impact elemental cycles of carbon, nitrogen, iron, sulfur, etc. are generally not known. This presents an enormous challenge to understanding, at a very basic level, the global implications of the presence of deep ecosystems. Does this biosphere impact Earth processes such as energy and carbon cycling, and can a better understanding of its function help solve global redox and carbon budgets? To meet these challenges new drilling and sampling are required to obtain high-quality fresh samples critical for microbiological and biogeochemical study.
Research on the deep subseafloor biosphere has the potential to address urgent questions about energy creation, climate change, and the nature of evolution of life on Earth over geologic time.

Important emerging fields within paleontology are the study of systems ecology and biotic response to major environmental forcing (such as climate change). Drilling is needed to better understand how ecosystems influence and respond to their environment on different timescales in order to predict how populations will respond to present and future global change. High temporal resolution records across paleogeographic gradients and through time can thus be used to study the processes that generate and destroy biodiversity.

\section{Human-Earth-Human Interactions}

\section{Geohazards}

A top priority for the new drilling program should be the study of geologic hazards. Geology touches society directly through earthquakes, tsunamis, and landslides, and drilling can provide key constraints. Ocean drilling can be combined with other onshore and offshore national and international 
geohazards programs to provide knowledge for hazard assessment and mitigation of earthquakes and tsunamis that have the potential to directly impact the majority of the world's population, as well as for submarine slides that are of great concern to subsea and coastal infrastructure.

Research over the past decade indicates that old models of only two types of failure, stick-slip and creep, are incorrect. Slow-slip events, very low frequency earthquakes, and tsunami earthquakes are part of the stress-strain cycle (Fig. 4), and with the recent Haiti earthquake ( $\mathrm{Mw}$ 7.0) there is recognition that even modest events can potentially cause a devastating loss of life. Specific queries for a drilling-based study of earthquake geohazards include the following: What is the nature of large-slip zones in earthquakes? What controls the size of earthquakes? Are very large destructive earthquakes governed by the same processes as small earthquakes? What are the characteristics of the earthquake repeat cycle? What causes tsunami earthquakes? What con-

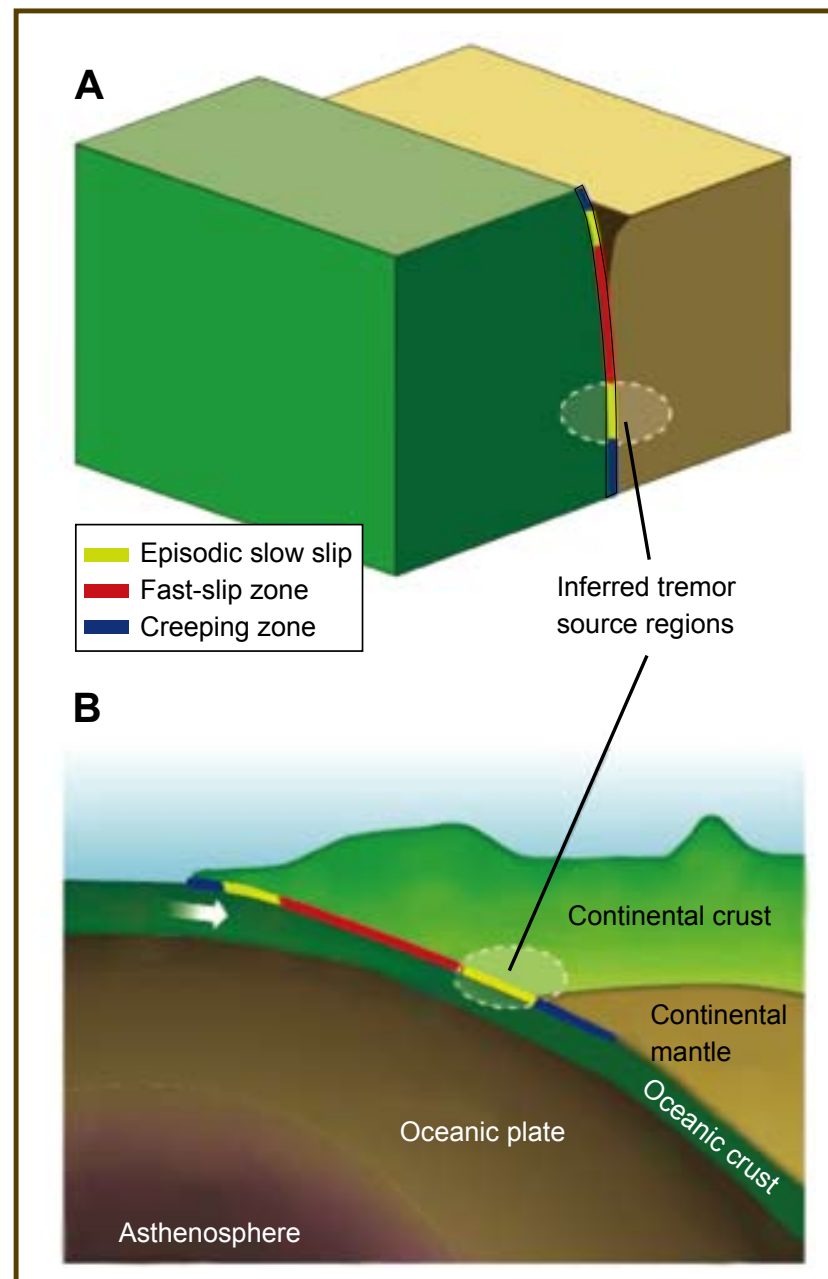

Figure 4. Locations of brittle fast-slip (seismogenic) and slow-slip zones: [A] Vertical strike slip fault; [B] Subduction zone. The new paradigm in earthquakes includes not only classically understood locked zones that break in fast slip producing earthquakes and adjacent creeping zones that nearly continuously deform without generating earthquakes, but also faults with episodic slow-slip zones that produce tremors. Additionally some subduction zones generate tsunami earthquakes that produce inordinately large tsunamis compared to the size of the earthquake (from Kanamori, 2008). trols the range of tsunami efficiency generated by different earthquakes? Are earthquakes on different types of faults (e.g., subduction megathrusts vs. plate-boundary strike-slip faults) fundamentally the same or different? To answer these questions requires drilling using a range of platforms, sampling, and logging strategies, integration with observatories and modeling, and collaboration with onshore studies.

Submarine landslides occur at a wide range of scales and settings. They often comprise distinctive mass-transport deposits recognized on the seafloor or in seismic reflection profiles. Small-scale submarine landslides are relatively frequent. They have displaced oil rigs, damaged pipelines, broken deep-sea communication cables, and devastated segments of coastline. Large- and small-slide events along coastal zones also create local, destructive tsunamis. A variety of triggers have been implicated in the initiation of submarine landslides, including earthquakes, sea-level change, and gas hydrates. There are important questions for examining this geohazard. How safe is the ocean floor? What causes and triggers submarine landslides? What are the frequencies and magnitudes? Is there a size-frequency relationship to submarine landslides? What is the relationship between climate change and submarine landslides? What is the tsunamigenic potential of past and future slides? Can and do gas hydrates cause seafloor instabilities? Can submarine slides cause significant hydrate dissociation? To study these processes requires drilling into past slides and into slide-prone areas to examine rheologic, hydrologic, lithologic, and geotechnical controls on slope stability through sampling, logging, and monitoring.

\section{Exploring the Future, Anticipating the Transition to a High $\mathrm{pCO}_{2}$ World}

Increasing atmospheric carbon dioxide content $\left(\mathrm{pCO}_{2}\right)$ is the main driving force for projected future climate change. One of the primary goals of climate-change research is to quantify the Earth's equilibrium climate sensitivity, which is a measure of the climate-system response to sustained radiative forcing caused by changes in atmospheric greenhouse gas contents. Although it is defined as the equilibrium global average surface warming following a doubling of $\mathrm{CO}_{2}$ and greenhouse gas equivalent concentrations, a broader definition would include the sensitivity of the entire Earth system to feedback processes that operate over a wide range of timescales. Phenomena that affect these processes include the carbon cycle, cloud cover, albedo, glacial processes, deep-ocean circulation, weathering, and acidification. Climate sensitivity may be non-linear (feedbacks affected by feedbacks), may differ regionally (such as at high latitudes where sea-ice albedo and other feedbacks may amplify climate change), and may affect the characteristics of climate variability (e.g., the response of climate to perturbations or external forcing in a warm-climate compared to a cold-climate state). 
Ocean drilling can deliver unique data necessary to quantify climate sensitivity in the past (Fig. 5) and contribute to understanding the feedback processes that need to be included for successful modeling of this topic of great societal relevance. Ocean sediments contain records of past temperatures, ocean chemistry, and $\mathrm{pCO}_{2}$ from a wide range of boundary conditions and time scales inaccessible by modern, historical, or ice-core records. In particular, continuous high-fidelity records from times with $\mathrm{pCO}_{2}$ levels higher than today are only obtainable through drilling ocean sediments deposited during warm intervals of the past. As such, ocean drilling provides the means to answer some of the key questions related to the quantification of climate sensitivity.

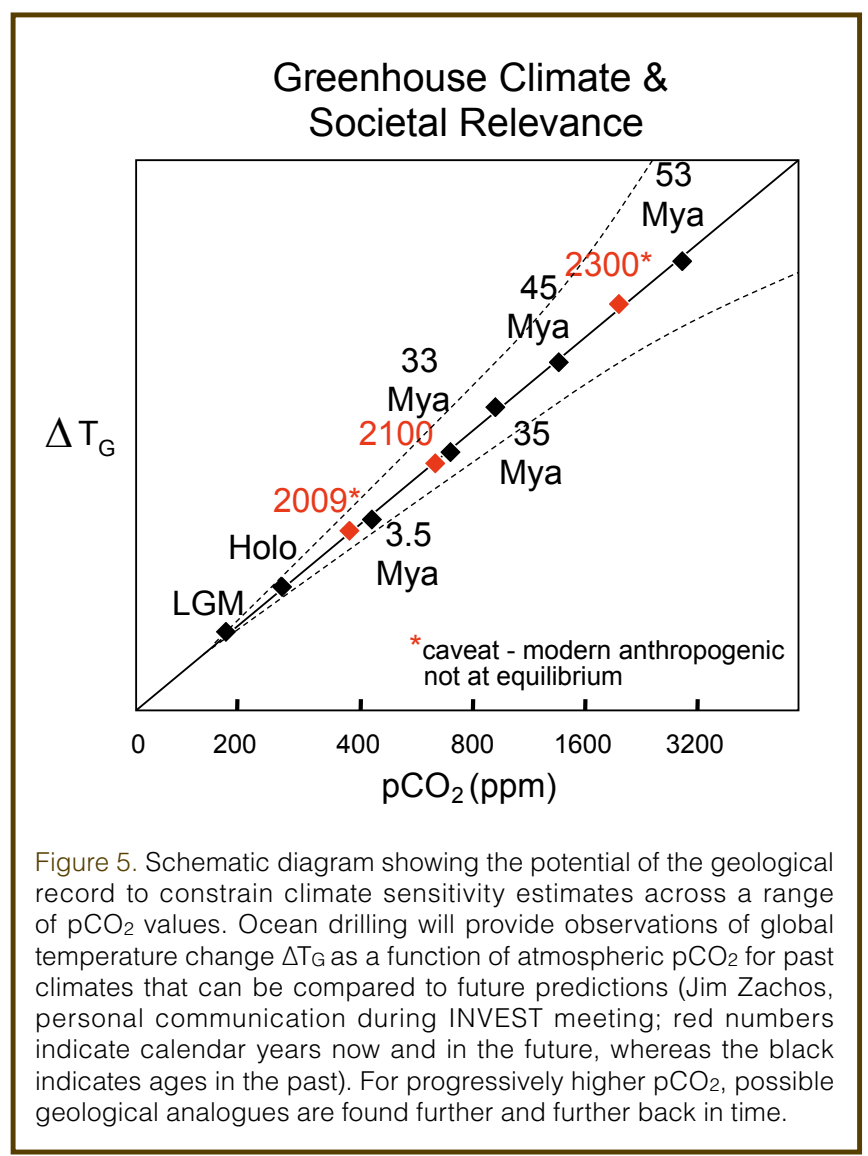

Increasing atmospheric $\mathrm{CO}_{2}$ levels will not only cause climate to change, but will also lead to ocean acidification, known as "the other $\mathrm{CO}_{2}$ problem". Acidification will affect bio-calcification, oceanic ecosystems, and carbon-cycle feedbacks. But, in the face of increasing $\mathrm{pCO}_{2}$, carbon-cycle feedbacks are as uncertain as the climatic response. Ocean drilling has already played a major role in framing the current concern about ocean acidification. Although ice-core records indicate that atmospheric $\mathrm{pCO}_{2}$ changes have only varied within a very narrow range during the past $\sim 800,000$ years, archives from times of significantly higher $\mathrm{pCO}_{2}$ can only be obtained through ocean drilling. These records provide the means to answer some key questions about the acidification process and the timescales over which the ocean is buffered. Ocean drilling will deliver key records of lysocline shoaling, atmospheric $\mathrm{pCO}_{2}$, carbonate ion concentrations, and biotic responses to changes in ocean acidity in order to quantify the feedbacks and enhance predictions of ocean acidification and its impacts. As such, ocean drilling can make a substantial and unique contribution to this field of immediate societal relevance.

Another urgent avenue of climate-change research is the study of factors that impact rates and amplitudes of sea-level change. The response of ice sheets (and thus sea level) to climate change is difficult to constrain because of the complexity, size, and relatively slow response of ice sheets. Since instrumental records of sea level extend back only about 150 years, refinement of predictions of sea-level rise clearly rely on past high-resolution records of the rates and magnitude of rapid sea-level change.

During glacial-interglacial transitions known as terminations, ice volume decreased, and temperatures, greenhouse gas concentrations, and sea level (magnitude $>100 \mathrm{~m}$ ) increased abruptly. Those periods are therefore regarded as potential analogues for future rapid sea-level rise and coeval abrupt climate change. The reconstruction of rates and magnitudes of sea-level rise during several terminations may help to model ice-sheet dynamics, clarify the mechanisms and sources of catastrophic ice-sheet collapse, understand suborbital climate variability, and determine the timing and volume of meltwater release under varying thermal regimes during deglaciations. In addition, gaining a much better understanding of the dynamics and sensitivity of Greenland, West Antarctic, and East Antarctic ice sheets to climate change during past warm periods is only attainable through ocean drilling, and is critically important to validating and improving ice-sheet and climate models used to predict future sea-level changes.

\section{Cross-Disciplinary Research Frontiers}

\section{Extreme Events}

Earth history, on the human and the geologic timescales, is punctuated by extreme events. Increasingly, we have discovered that intermittent, abrupt departures from stable, steady-state conditions can have major impacts on the Earth's environment, the evolution of life, and global biogeochemical cycles. The study of extreme events links many high priority science goals, crosses several broad themes, and will answer fundamental questions about evolutionary processes, and thresholds in the Earth system that, if passed, lead to dramatic ecosystem responses. For example, the processes that dictate changes in biodiversity, the oceanographic and climatic drivers of ecosystem assembly and change, speciation, and extinction can be studied through drilling of extreme events such as mass extinctions and hyperthermals. Bolide impacts and episodes of catastrophic volcanism are examples of abrupt perturbations that have left geologic records whose study will address these issues. 
Future drilling can play a vital role in improving our understanding of impacts and their role in Earth's history, particularly through comparison of impacts that caused mass extinction events (e.g., the 65.5 Ma Chicxulub impact) to other large impacts that only caused minor perturbations (e.g., the 35 Ma Chesapeake Bay impact). Identifying the critical factors that lead to global environmental devastation (e.g., the energy of impact, the chemistry of the target rocks, additional environmental stresses, or the vulnerability of life at the time of impact) is possible through ocean drilling of the impact structures and the sediments containing critical fossil and environmental-proxy evidence.

A fundamental process within the solid Earth is intermittent whole-mantle overturn that results in periods of eruption of large igneous provinces (LIPs) (Fig. 6), high seafloor spreading and associated arc collisions, and sea-level highstands. This mode was last prominent during the Cretaceous to early Tertiary Periods (135-55 Ma) when extraordinary eruption rates produced large igneous systems on both continents and in ocean basins. The rate, volume, and duration of these events need to be constrained to understand the geodynamic mechanisms for their origin and their potential environmental impacts, including mass extinctions, rapid global warming, ocean acidification, and oceanic anoxic events. LIPs are extreme mantle-melting and volcanic events that can be studied to answer questions about geodynamic models whose critical distinctions are magma flux through time, geochemical variability, and internal architecture-all of which are best addressed by drilling to obtain direct volcanic samples and far-field, high-resolution marine sedimentary sections.

\section{Hominin Evolution}

Scientific ocean drilling can transform our understanding of how African climate change affected early human evolution. Key evolutionary events occurred near 3.0-2.5 Ma and 2.0-1.5 Ma that effectively shaped the characteristics that define us as human: bipedalism, exceptionally large brains, and the construction of increasingly sophisticated stone tools. Environmental hypotheses for early human evolution suggest that changing African climate altered the ecological composition of a landscape, which led to specific faunal adap- tation or speciation pressures that resulted in genetic selection and innovation. Where hypotheses differ is in the proposed role of climate change in natural selection. The Savannah Hypothesis states that the evolution of African mammalian fauna, including early hominins, was primarily linked to the progressive expansion of more open grassland conditions. The Turnover Pulse Hypothesis is the variant of this idea that focuses on bursts of biotic change initiated by progressive shifts toward greater African aridity at approximately 2.8 Ma and 1.8 Ma. The Variability Selection Hypothesis suggests that changes in the amplitudes of orbitally controlled African climate variability, linked to the eccentricity modulation of precessional monsoonal cycles, may have been an important genetic selection criterion. To test these hypotheses, fundamental questions concerning the timing, nature, and causes of African climate variability must be answered. Drilling targets are margin sediments that reflect the subtropical African geographic domain where hominin fossils are found, including South Africa, Tanzania, Kenya, and Ethiopia. Ocean drilling to obtain records from these regions will likely revolutionize our understanding of the timing and causes of African climate changes and allow us to test the hypothesized role of past climate changes in shaping the course of human evolution.

\section{Climate-Tectonic Linkages and Feedbacks}

Climate and plate tectonics are two forces that shape the Earth in concert; examining the interplay between climatic and tectonic processes will advance our understanding of 
both. Fundamental questions regarding tectonic-climate linkages can be answered by ocean drilling in conjunction with continental studies. Future studies should focus on how the changing configuration and topography/bathymetry of the continents and oceans influence ocean and atmospheric circulations and biogeochemical cycles, as well as how orogens respond to significant climate shifts such as the onset of Northern Hemisphere glaciation, the Mid-Pleistocene Transition, and the development of the Indian monsoon. Other avenues of research should investigate how tectonics influences discharge of freshwater, nutrients, and sediment from the continents to the ocean and how these affect the biota and biogeochemical cycles on continental margins and in marginal seas. The potential impact of small rivers, groundwater, and eolian transport on global freshwater, nutrient, and sediment budgets also needs to be quantified. Future ocean drilling should focus on capturing a complementary array of continental margin and fan records, including Arctic and Antarctic deposystems; exhumation history; terrestrial climate/vegetation changes; sediment, nutrients, and carbon budgets; and freshwater discharges for the areas of the Earth with the highest fluxes. Such a strategy will undoubtedly advance our understanding of the feedbacks between tectonics and climate and their combined influences on the Earth's surface.

\section{Technological Needs and Development}

To achieve novel scientific ocean drilling objectives will depend on improved drilling capabilities such as enhancing depth penetration, improving core recovery and quality, coring in high-temperature and high-pressure environments, coring in shallow water margins, coral reefs, and sea-ice covered regions (e.g., such as with the planned Research Icebreaker Aurora Borealis), and preventing magnetic, chemical, and microbiological contaminations. Overall, the next phase of the scientific drilling program will require significant and even more coordinated engineering efforts.

One of the most significant technological requirements is the measurement of the intrinsic and/or ephemeral properties of cores and boreholes. In situ measurements of redox state, chemical compositions, physical parameters, $\mathrm{pH}$, and microbial populations and their activities are absolutely necessary. Newly developed (or improved) logging sensor tools, in situ sampling/monitoring devices, and in situ microbial colonization systems will be needed to achieve multidisciplinary scientific objectives through borehole observatories and experiments. Real-time hydrocarbon gas monitoring systems that include stable isotope measurements should also be deployed in platform laboratories. Novel and/or improved analytical technologies for quick, high-resolution measurements of temperature-, redox-, and oxygen-sensitive chemical and microbiological components must be developed for use on recently acquired cores, since exploration of high-temperature hydrothermal systems and the deep, hot biosphere has great potential to increase our understanding of the co-evolution of life and the planet. In addition, onboard measurements of physical, chemical, and biological properties of cores are extremely useful for real-time decisions necessary to meet drilling goals.

The development of a high-pressure- (and -temperature) coring system is required for various geochemical and biological reactions because the pressure limit of the currently available high-pressure-coring system is up to $25 \mathrm{MPa}$, which is not enough for high-pressure gas fields or deep coring ( $>2500$ meters below the sea surface). Furthermore, once core under high pressure and temperature reaches the surface, an onboard high-pressure core transfer system equipped with multiple (micro-) sensors, gas and fluid extraction ports, tracer injection systems, and a mini-core sub-sampling system is needed.

Subseafloor microbes proliferate in narrow niches and vary over local fluid-flow pathways used to transport energy and nutrients, hence high-resolution microbiological sampling is necessary. We need to develop onboard sub-sampling strategies for quick identification of microbially interesting zones and high-resolution sampling capabilities while monitoring and minimizing contamination. Furthermore, the non-destructive identification of core quality and structures (through X-ray CT scanning) is a high priority for future microbiology/biogeochemistry-dedicated drilling expeditions. For high-throughput and high-resolution onboard analyses, computer automated systems, such as the auto-extractor and the automated cell-counting microscope system using fluorescent image analysis, should be deployed.

Penetration through a complete ocean-crust section, the so-called project "Mohole", will require advances in drilling capabilities that include riser drilling capability in $4000 \mathrm{~m}$ or more water depth, deep penetration and recovery of crustal rocks of all lithologies, and borehole and drill bit cooling technology for high temperature $\left(>250{ }^{\circ} \mathrm{C}\right)$ environments. Technological issues include improvement of riser-pipe quality and casing strings, the blowout preventer, and the mud-circulation/recovery system.

The newly developed Riserless Mud Recovery (RMR) system has great potential for use in various environments in future drilling, especially for borehole controls (i.e., stability and cooling). Combining the dual-gradient technology with RMR enables environmentally friendly drilling (i.e., clean without mud pollutants to seawater) access to deeper environments and areas previously not drillable by riserless drilling. The RMR technology is directly applicable to all IODP platforms.

Improving core recovery and quality is the fundamental challenge for all drilling environments. Core recovery and quality depend on factors such as depth, temperature, fluid pressure, and lithology, as well as the design and perfor- 
mance of drilling and coring tools. In previous drilling experiences, poor core recovery has plagued (a) chert and/or shales, (b) sand and gravel layers, (c) hydrothermal deposits, (d) rubble basalts and sheeted dyke complexes, and (e) fault and fracture zones. Anticipated improvements include more accurate compensation of drill bit motion, torque, and type of cutting shoe, and operational technologies such as a feedback system of real-time drilling parameters. Other strategies, such as cuttings and side-wall coring, will increase sampling of unrecovered intervals. Borehole management (i.e., stability) requires cuttings removal and compensation of lithostatic and pumping pressures in both riser and riserless drilling modes. In addition, large diameter pipes may provide more opportunities to conduct various geophysical measurements such as pore pressures and resistivity.

Monitoring while drilling using downhole logging tools has greatly expanded our understanding of in situ pressure and stress conditions in the borehole. The use of logging tools during drilling or in CORKed boreholes is likely to expand in the new drilling program. Multiple-hole experiments are recommended, including injection tests and cross-borehole communication studies. Broadband and high-sensitivity sensors such as fiber-optic seismo-sensors combined with continuous data recovery should be developed and installed in active subseafloor environments. To study in situ conditions of high-temperature and/or high-pressure environments, the durability of logging systems to high temperature and pressure must be improved. Development of new slim-line multi-logging tools and borehole equipment is needed for all platforms. Current shipboard computational and dissemination capabilities should be more effectively integrated between software programs, database mining, and accessibility and be easily interfaced among the multiple drilling platforms and core repositories.

\section{Outreach and Education, and Branding}

Outreach refers to activities that target the general public and funding agencies. Education and educational outreach are aimed at students in primary, secondary, undergraduate, and graduate school realms. Continued coordination through IODP-MI or its successor organization is essential to achieve the best results in the arena of public outreach. A successful branding campaign will be vital to ensure ongoing public recognition of the scientific discoveries and technological achievements of scientific ocean drilling.

Branding the science and accomplishments of ocean drilling should elucidate the linkages to broader objectives or themes, and not necessarily focus on individual expeditions. As visual impression is the key for branding, web sites across the program must have a common layout to promote the impression of a truly integrated program to the scientific community and the public, and to facilitate access to infor- mation. A series of bold, clear key messages should be an important element in any branding campaign. For example, the main messages of the drilling program should emphasize the following:

- The program investigates a dynamic Earth; it is a changing, not static, planet.

- Basic science is always valuable to society.

- Scientific ocean drilling is particularly relevant to society, providing knowledge about geohazards and climate change.

- Scientific ocean drilling is on the edge of the science frontier. By exploring Earth through scientific ocean drilling, we make novel and fundamental discoveries.

Outreach and education are vital in raising the profile of the future drilling program. The program needs to employ a full-time science "translator" (scientist or science educator with requisite skills) that can effectively communicate drilling science to non-scientists. Because many ocean drilling scientists are also geoscience educators, there should be mechanisms for them to be closely involved in framing the science to be easily accessible to students and the general public. Consideration should be given to expanding successful current programs to include all international partners and to serve all audiences (undergraduates, graduates, faculty, young scientists, science teachers, etc.). Specific recommendations are (a) the development and dissemination of an archive of basic images documenting the history and goals of the drilling program; (b) admitting science educators, in addition to school teachers, on expeditions; (c) providing communications training for younger scientists on board; (d) offering early career workshops sponsored by the new ocean drilling program; and (e) developing a mentoring plan for young career scientists who go to sea on expeditions and site survey cruises. Generally, the ocean drilling program should make greater use of Google Ocean and GeoMapApp to provide the public with images and video for education and outreach. Finally, in planning the new drilling program, there should be a workshop dedicated to formulating a plan that employs innovative cutting-edge methods of science education, communication, and outreach.

\section{Recommendations for the Architecture of a New Program}

Scientific planning in the new ocean drilling program should be driven from the "bottom up", with scientists playing key roles in defining specific scientific short- and long-term goals and in advising and working directly with management, ship operators, and engineering development to execute the drilling program. The direct involvement of world-class students and scientists will keep the international ocean drilling program fresh and focused on emerging transformative topics that define the frontiers of life and earth sciences. As such, a strong science advisory structure should be a central component of the new program architec- 
ture. Furthermore, transformative science is often born from cross-disciplinary perspectives, and the drilling program must have multiple mechanisms to proactively engage scientists and students from disciplines outside of the traditional drilling community, from both academia and industry.

Because of the complex nature of an international drilling program with multiple operators and stakeholders, effective management should focus on fostering stronger international partnerships, well-integrated collaborations with other large geosciences programs, effective fundraising, and creative and efficient coordination amongst the national offices and implementation/ship operators. By working with the science advisory committees and scientific community, management should facilitate the formulation of visionary and innovative scientific goals through the life of the program.

Meeting the scientific goals of the drilling program will require flexibility. Multi-expedition, long-term missions will be required to achieve these ambitious goals. At the same time, many of the highest impact ocean drilling projects may be unanticipated and/or concise and focused. Thus, there must be mechanisms by which the new ocean drilling program can quickly respond to, nurture, and execute brilliant new ideas (identified through a peer-review system) that require ocean drilling. To implement the projects necessary to achieve transformative science will require a new ocean drilling program architecture that, by design, will have the flexibility to react quickly to new opportunities, but also to make decisive commitments to long-term complex, technically challenging projects.

\section{References}

Inagaki, F., 2010. Deep subseafloor microbial communities. In Encyclopedia of Life Sciences, Chichester (John Wiley \& Sons, Ltd.), doi:10.1002/9780470015902.a0021894.

Kanamori, H., 2008. Earthquake physics and real-time seismology. Nature, 451:271-273, doi:10.1038/nature06585.

Teagle, D., Abe, N., Bach, W., Blackman, D., Coggon, R., Dick, H., Edwards, K., and Ildefonse, B., 2009. Melting, magma, fluids and life: Challenges for the next generation of scientific ocean drilling into the oceanic lithosphere, Workshop Report, 27-29 July 2009. National Oceanography Centre, Southampton, University of Southampton, U.K., 85 pp.

Thurow, J., Peterson, L.C., Harms, U., Hodell, D.A., Cheshire, H., Brumsack, H.J., Irino, T., Schulz, M., Masson-Delmotte, V., and Tada, R., 2009. Acquiring high to ultra-high resolution geological records of past climate change by scientific drilling. Sci. Drill., 8:46-56, doi:10.2204/iodp.sd.8.08.2009.

\section{Authors and Steering Committee Members}

Wolfgang Bach (co-chair), Department of Geosciences, University of Bremen, Klagenfurter Strasse, D-28359 Bremen, Germany.

Christina Ravelo (co-chair), Ocean Sciences Department, University of California Santa Cruz, CA 95064, U.S.A., e-mail: acr@ucsc.edu (corresponding author).

Jan Behrmann, Leibniz-Institut für Meereswissenschaften, IFM-GEOMAR, Gebäude Ostufer, Wischhofstrasse 1-3, 24148 Kiel, Germany.

Gilbert Camoin, National Center for Scientific Research (CNRS), CEREGE UMR 6635, CNRS, Europôle Méditerranéen de l'Arbois, BP 80, F-13545 Aix-en-Provence cedex 4, Aix-en-Provence, France.

Robert Duncan, College of Oceanic and Atmospheric Sciences, Oregon State University, 104 COAS Administration Building, Corvallis, OR 97331-5503, U.S.A.

Katrina Edwards, Department of Biological Sciences, Hancock Auditorium and Museum (AHF) 107F, University of Southern California, Los Angeles, CA 90089-0371, U.S.A. Sean Gulick, The University of Texas at Austin, Department of Geological Sciences, Geology Building 2. 106, 23rd Street at San Jacinto Boulevard., Austin, TX 78705, U.S.A.

Fumio Inagaki, Kochi Core Center, JAMSTEC, 200 Monobe Otsu, Nankoku City, Kochi Prefecture, 783-8502, Japan.

Heiko Pälike, National Oceanography Centre Southampton, University of Southampton and Natural Environment Research Council, Southampton, University of Southampton Waterfront Campus, European Way, Southampton, SO14 3ZH, U.K.

Ryuji Tada, Department of Earth and Planetary Science, University of Tokyo, Sci. Bldg. No.1-734, Hongou 7-3-1, Bunkyo-ku, Tokyo, 113-0033, Japan. 